Rev. 0

\title{
9975 SHIPPING PACKAGE LIFE EXTENSION SURVEILLANCE PROGRAM RESULTS SUMMARY
}

\author{
W.L. Daugherty ${ }^{1}$ \\ K.A. Dunn ${ }^{1}$ \\ E.R. Hackney ${ }^{2}$ \\ E.N. Hoffman ${ }^{1}$ \\ T.E. Skidmore ${ }^{1}$ \\ ${ }^{1}$ Savannah River National Laboratory \\ Materials Science \& Technology \\ ${ }^{2}$ Nuclear Materials Management Engineering
}

Publication Date: January 2011

Savannah River Nuclear Solutions

Savannah River Site

Aiken, SC 29808

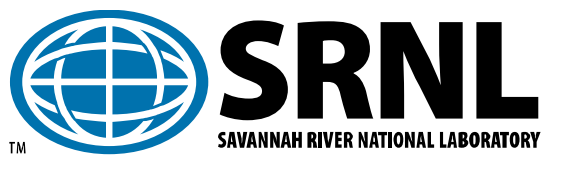

This document was prepared in connection with work done under Contract No.

DE-AC09-08SR22470 with the U. S. Department of Energy. 
SRNS-STI-2010-00763

Rev. 0

\section{DISCLAIMER}

This report was prepared as an account of work sponsored by an agency of the United States Government. Neither the United States Government nor any agency thereof, nor any of their employees, makes any warranty, express or implied, or assumes any legal liability or responsibility for the accuracy, completeness, or usefulness of any information, apparatus, product, or process disclosed, or represents that its use would not infringe privately owned rights. Reference herein to any specific commercial product, process, or service by trade name, trademark, manufacturer, or otherwise does not necessarily constitute or imply its endorsement, recommendation, or favoring by the United States Government or any agency thereof. The views and opinions of authors expressed herein do not necessarily state or reflect those of the United States Government or any agency thereof. 
SRNS-STI-2010-00763

Rev. 0

\section{SHIPPING PACKAGE LIFE EXTENSION SURVEILLANCE PROGRAM RESULTS SUMMARY}

APPROVALS:

W. L. Daugherty

Date

Author, Materials Science and Technology

K. A. Dunn

Date

Lead Author, Pu Surveillance Program Lead, Materials Science and Technology

E. R. Hackney

Date

Author, NMSP Engineering

E. N. Hoffman

Date

Author, Materials Science and Technology

T. E. Skidmore

Author, Materials Science and Technology

R. L. Huffines

Date

NMSP N\&CSE Area Manager

N. C. Iyer

Date

Director, Materials Science and Technology Directorate

M. J. Lewczyk

Date

KAC Facility Manager

T. M. Monahon

Date

NMSP Engineering Manager

REVIEWS:

J.W. McEvoy

Date

9975 Design Authority

D.R. Leduc

Date

Savannah River Packaging Technology 


\section{Revision Log}

Document No. SRNS-STI-2010-00763 Rev. No. 0

Document Title 9975 SHIPPING PACKAGE LIFE EXTENSION SURVEILLANCE PROGRAM RESULTS SUMMARY

$\begin{array}{llll}\text { Rev. \# } & \text { Page \# } & \text { Description of Revision } & \text { Date } \\ 0 & \text { All } & \text { Original document } & 1 / 6 / 11\end{array}$




\section{Summary}

Results from the 9975 Surveillance Program at the Savannah River Site (SRS) are summarized for justification to extend the life of the 9975 packages currently stored in the K-Area Materials Storage (KAMS) facility from 10 years to 15 years. This justification is established with the stipulation that surveillance activities will continue throughout this extended time to ensure the continued integrity of the 9975 materials of construction and to further understand the currently identified degradation mechanisms.

The current 10 year storage life was developed [1] prior to storage. A subsequent report [2] was later used to extend the qualification of the 9975 shipping packages for 2 years for shipping plus 10 years for storage. However the qualification for the storage period was provided by the monitoring requirements of the Storage and Surveillance Program. This report summarizes efforts to determine a new safe storage limit for the 9975 shipping package based on the surveillance data collected since 2005 when the surveillance program began.

KAMS is a zero-release facility that depends upon containment by the 9975 to meet design basis storage requirements. Therefore, to confirm the continued integrity of the 9975 packages while stored in KAMS, a 9975 Storage and Surveillance Program was implemented alongside the DOE required Integrated Surveillance Program (ISP) for 3013 plutonium-bearing containers. The 9975 Storage and Surveillance Program performs field surveillance as well as accelerated aging tests to ensure any degradation due to aging, to the extent that could affect packaging performance, is detected in advance of such degradation occurring in the field. The Program has demonstrated that the 9975 package has a robust design that can perform under a variety of conditions. As such the primary emphasis of the on-going 9975 Surveillance Program is an aging study of the 9975 Viton $^{\circledR}$ GLT containment vessel O-rings and the Celotex ${ }^{\circledR}$ fiberboard thermal insulation at bounding conditions of radiation and elevated temperatures. Other materials of construction, however, are also discussed.

\section{Introduction}

The K-Area Complex (KAC) stores 9975 packages with 3013 containers in KAMS. These packages were loaded as early as 2001 at the Rocky Flats Environmental Technology Site (RFETS) in compliance with the 9975 SARP and Certificate of Compliance (CoC). The earliest leak test dates were during 2000. The acceptance of these packages beyond their annual maintenance is based on [3] and a surveillance program was put in place to provide materials performance projections.

All 9975 shipping packages containing a 3013 selected for DE or NDE are nondestructively examined when the 3013 undergoes surveillance. Field surveillance activities of the 9975 shipping packages began in FY05 and are currently performed in KAC. The destructive examination (DE) of one 9975 shipping package per year also began in FY05. Destructive examinations and material testing are performed at the 
Savannah River National Laboratory (SRNL). A Surveillance Program summary is provided in WSRC-TR-2001-00286, Rev. 5 [4].

The results from the 9975 surveillance program are summarized herein to provide the technical justification for extending the 9975 shipping package from a 10 year storage life in KAMS [3] to a 15 year storage life in KAMS.

\section{Background}

The SRS is storing plutonium $(\mathrm{Pu})$ materials in the KAC. The Pu materials are packaged per the DOE 3013 Standard [5] and shipped to SRS in Model 9975 shipping packages. The 9975 packages are also used for interim storage in the 105-K building. The 9975 is a robust drum style Type B RAM Packaging meeting all regulatory requirements with a large margin of safety for transportation. It utilizes a double-containment vessel packaging which exceeds the current transportation requirement of single-containment for plutonium. Two different models of the 9975 shipping package are used to store plutonium at KAMS. The first model is referred to as the -85 package. The second model is called the -96 package and is now being fabricated as the new shipping package, due to the -85 type packages no longer being made.

The following overview describes the general configuration of both the -85 and -96 shipping packages. Figure 1 at the end of this report shows a three-dimensional sectional view that is valid for both packages [6,7].

Both shipping packages each use an outer drum with nominal capacity of 35 gallons that is made from 18-gauge Stainless Steel (SS) 304L. The maximum gross weight of each shipping package is set at 404 pounds, which includes the maximum payload weight of 44.4 pounds that goes into the Primary Containment Vessel (PCV) of the package. Each payload consists of plutonium material, which can be in oxide or metal form, the packing components (e.g., food pack can or convenience can), and the surrounding 3013 container.

The external drum has four $1 / 2$-inch diameter vent holes drilled into its outer perimeter. These holes are located 90 degrees apart, one inch below the drum flange, and each one is fitted with a plastic plug (i.e., a Caplug ${ }^{\circledR}$ ). The plugs will burn or melt when exposed to the heat of fire. The four holes allow hot gases (e.g., water vapor, volatiles), evolved from the Celotex ${ }^{\circledR}$ fiberboard insulation during pyrolysis, to vent from the drum to prevent its rupture. Celotex ${ }^{\circledR}$ is the brand name of a commercially available fiberboard that is made from sugarcane bagasse or softwood in accordance with ASTM Specification C208 [8]. It has a nominal density of 16 pounds per cubic foot [6,7]. Both cane and wood-based types of fiberboard are made by Knight-Celotex ${ }^{\text {м }}$ Company, and the two can be used interchangeably in the 9975 package.

The radiation shielding body for each shipping package is a lead cylinder that surrounds both the PCV and the Secondary Containment Vessel (SCV). Together, the PCV and SCV form the double containment assembly. The -85 package uses a shielding body that 
has a 20-gauge SS-304 liner laminated to the inner surface of the open cylinder. The lead shield for the -96 package incorporates an additional 20-gauge SS-304 jacket on the outer surface of the cylinder; this inhibits the formation of lead carbonate corrosion product, and contains any that might form. Both shielding bodies fully meet the specified requirements for radiation protection in shipping packages and are equivalent.

The PCV is a stainless steel pressure vessel that meets Section III, Subsection NB of the ASME code, without the code stamp. The closure assembly is a slightly tapered SS plug that uses redundant O-rings to form a leak-tight seal on the PCV. The SCV is a stainless steel pressure vessel, identical to that of the PCV except for its larger volume, which is designed to accommodate a fully loaded PCV with the closure assembly installed. The SCV also uses a tapered SS plug with two O-rings for its closure. The O-rings used in both closure assemblies are made from fluorocarbon rubber, which is available as Parker Viton ${ }^{\circledR}$ Compound V0835-75 or VM835-75. These two compounds are equivalent.

The KAC DSA (Document Safety Analysis) credits the 9975 package to perform several safety functions, including containment, fire resistance, criticality control, and impact resistance to ensure the plutonium materials remain in a safe configuration during normal and accident conditions [9]. The 9975 package was approved and expected to perform its KAC safety function for at least 12 years from initial packaging (or 10 years from receipt in KAMS). The DSA recognizes the potential for degradation of the materials of package construction over time in the KAC storage environment and requires the assessment of the adequacy of materials performance to validate the assumptions of the analysis and ultimately predict service life. Therefore, SRS performs surveillance on a select number of 9975 shipping packages from KAC and employs a complementary shelf-life program for bounding KAC conditions [10].

The primary focus of the SRS 9975 Pu Storage and Surveillance program includes the containment vessel O-rings and the insulating material, Celotex ${ }^{\circledR}$ fiberboard. The 9975 shipping package (Figure 1) contains nested stainless steel primary and secondary containment vessels (PCV/SCV). The containment vessels are closed with a threaded cone-seal plug sealed with dual O-rings (Figure 2). For both vessels, the outer O-ring is part of the containment boundary. The inner O-ring provides a test volume for post-load leak testing and provides another material release barrier, but is not credited for containment $[6,7]$.

Two O-ring compounds, currently approved for use in the 9975 packages, are Parker Seals V0835-75 (hereafter referred to as Viton ${ }^{\circledR}$ GLT) and VM835-75 (hereafter referred to as Viton ${ }^{\circledR}$ GLT-S). Viton ${ }^{\circledR}$ GLT was specifically developed in the 1970s to allow peroxide curing and improve low-temperature performance. These polymers are widely used in many applications and industries including aerospace, military, chemical and automotive. They are approved for use in the 9975 shipping package and other radioactive material packages $(9977,9978)$ for their excellent balance of properties. The GLT-S O-ring compound was evaluated and approved as an equivalent substitute when the O-ring compound manufacturer identified that the base polymer (Viton ${ }^{\circledR}$ GLT) for the O-rings would no longer be produced [11]. 


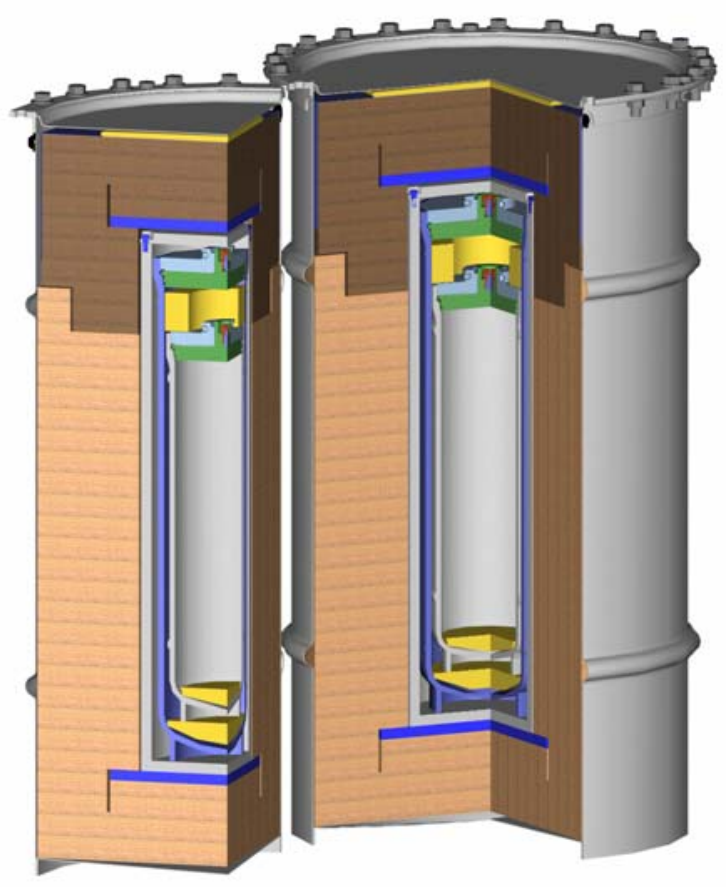

Figure 1. Cutaway of 9975 shipping package

Celotex ${ }^{\circledR}$ fiberboard is contained between the outer 304L stainless steel drum and the lead shielding in the 9975 package. The fiberboard provides three safety functions: thermal insulation to limit PCV/SCV temperature during a fire, criticality control and resistance to package crushing. The fiberboard used in 9975 packages can be either cane fiberboard insulation or softwood fiberboard insulation, per ASTM C208-95, Grade IV wall sheathing. Layers of fiberboard are laminated together with an Elmer's ${ }^{\circledR}$ Professional Carpenters wood glue (a water-based polyvinyl acetate (PVAC) adhesive). Celotex ${ }^{\circledR}$ fiberboard is composed of cellulose $(\leq 96 \%)$, starch $(\leq 10 \%)$, clay $(\leq 2 \%)$, carbon black $(<0.5 \%)$, paraffin wax binder $(\leq 2 \%)$ and a lamination adhesive $(\leq 3.5 \%)$ [6,7]. Analysis also confirmed that the material contains approximately 400-500 ppm chloride [12].

The fiberboard is contained within the 35 gallon 304L stainless steel drum and topped off with a flanged closure assembly. This closure assembly is not designed to maintain a weather seal. The caplugs on the body of the drum would not prevent water entry during immersion. There is a potential for water to infiltrate the 9975 package and reach the insulation material. 
SRNS-STI-2010-00763

Rev. 0

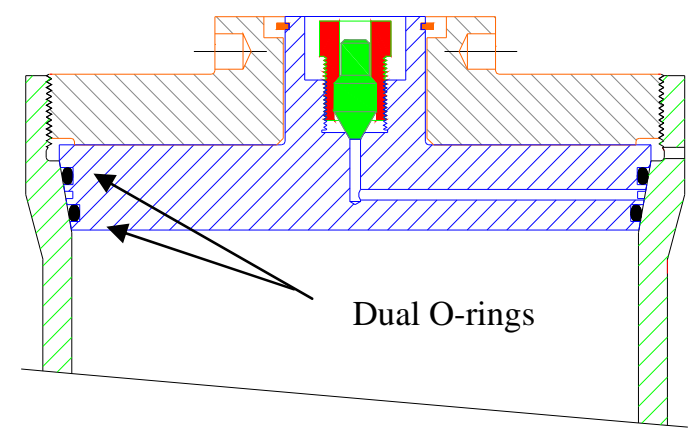

Figure 2. Containment vessel seal configuration.

As part of the initial effort to qualify 9975 containers for storage in KAC, the GLT Orings and Celotex ${ }^{\circledR}$ cane fiberboard materials were assessed to support a 2 year shipping plus 10-year interim storage period $[13,2]$. The assessment involved a detailed literature review and limited testing of artificially-aged O-rings, along with recommendations for a surveillance program. Subsequently, as a result of material changes, the GLT-S O-ring material and the Celotex ${ }^{\circledR}$ softwood fiberboard baseline properties were evaluated and compared with the GLT O-ring and cane fiberboard baseline properties and were found to be comparable [14]. For O-rings, the SRS Pu Storage and Surveillance Program for the 9975 encompasses three primary activities: 1) field surveillance and laboratory analysis of O-rings removed from the 9975 NDE packages, 2) helium leak testing of mock-up PCV fixtures aged at bounding storage conditions and 3) accelerated-aging studies based on compression stress relaxation (CSR). Information from all of these efforts is being used to develop a lifetime prediction model for GLT and GLT-S O-rings and ultimately validation of containment. In particular, tests are currently in progress to validate the early life prediction models based on short-term accelerated aging data and to, ideally, correlate sealing force with leak rate, as leak rate is the ultimate criterion for 9975 O-ring performance.

For fiberboard, the SRS Pu Surveillance and Storage Program for the 9975 encompass three primary activities 1) NDE field surveillance, 2) DE of one 9975 package annually and 3) accelerated aging studies. Data from these activities are analyzed to ensure the fiberboard properties continue to meet the minimum requirements for the KAC facility, including fire resistance [15], criticality [16], and impact properties [17].

\section{Program Results}

\section{Surveillance Approach}

The primary objective of the 9975 surveillance program is to monitor material performance and degradation in order to establish a basis for the service life and to provide advance notice of the need for repackaging 9975 shipping packages in KAC. This program is specific to SRS, since SRS is the only facility to store 3013 containers 
inside 9975 shipping packages. The surveillance approach uses a combination of NDE/DE field surveillance and lab testing to validate the 9975 performance assumptions of the safety basis, similar to the 3013 surveillance program. The 9975 shipping packages are expected to maintain safety performance in KAC beyond the normal period of certification as shipping packages based on engineering judgment and limited material performance data [9].

The field surveillances include NDE techniques (e.g. visual inspections, dimensional and weight measurements) on a limited set of 9975 packages to provide additional confidence that the material performance properties continue to meet their functional requirements. Acceptance criteria for field surveillance of the 9975 packages were developed. When an acceptance criterion is exceeded, the Surveillance Program Authority (SPA) initiates an evaluation to determine if the finding is deleterious to the package performance [4].

Laboratory tests examine the 9975 material components (e.g. O-rings \& fiberboard) at the bounding storage conditions as defined in the safety basis and monitor material properties and safety function performance over time. The tests are designed to accelerate material aging (via humidity, temperature, and radiation effects) and monitor and trend material properties in order to lead the actual field conditions. Additionally, the tests are designed to characterize and predict material changes (degradation) over time at the bounding conditions allowed in the safety basis before they are observed during field surveillance.

\section{O-Ring Performance - Containment}

\section{Field Surveillance - Actual Conditions:}

The predominant degradation mechanism for the containment vessel O-rings in 9975 packages is expected to be compression stress-relaxation or loss of sealing force due to long term exposure at elevated temperatures. Degradation due to radiation is much less likely at the bounding dose rates involved.

O-rings obtained from field surveillance activities following up to 8 years of storage in KAC have shown on average a small degree of compression set ( 23\%) based on nominal dimensions with no other evidence of degradation. The examined O-rings are observed to recover practically all roundness, with hardness and tensile properties similar to those of non-aged O-rings. The O-rings retain high flexibility and resiliency. Visually, there is no difference between the O-rings removed during field surveillance ( 23\% compression set) and new O-rings.

The O-rings examined to date have not been from maximum payload packages and have not seen postulated peak normal or accident conditions. In KAC the packages have been consistently stored well below $162^{\circ} \mathrm{F}$, with the maximum recorded ambient temperature in KAC being $106^{\circ} \mathrm{F}$ [18]. This translates to a peak O-ring temperature of $\sim 144^{\circ} \mathrm{F}$ for a $12 \mathrm{~W}$ payload, and a peak O-ring temperature of $\sim 166^{\circ} \mathrm{F}$ for a maximum $19 \mathrm{~W}$ payload. Therefore, the O-rings stored in KAC have yet to approach the calculated peak normal temperature of $200^{\circ} \mathrm{F}$. It is important to note that peak temperatures are not sustained on 
a continuous basis, as the ambient temperature in the KAC changes with outdoor ambient conditions, given adequate time for equilibration. For a more typical ambient temperature of $85^{\circ} \mathrm{F}$, the peak PCV O-ring temperature is further reduced to $\sim 145^{\circ} \mathrm{F}$ for a 19W payload. For packages with lesser payloads, seal temperatures are further reduced. These more moderate temperatures actually experienced to date in KAC ensure that the O-ring integrity remains conservatively bounded by laboratory test data. To date, the 9975 O-ring seals have not been significantly challenged by normal storage conditions in the KAC storage facility.

Three packages have failed the post load leak check which is performed prior to opening all 9975 PCV's and SCV's. The leak check is conducted using the same 9975 post load leak check procedure, used at the time of packaging, which simultaneously tests the pressure boundary on both the upper and lower O-rings. All three failed the leak check because the lower O-ring was determined to be leaking during the follow-up bubble testing. None of the more than 265 packages to undergo surveillance (or to be examined in KAMS for other reasons) have been identified to have a leaking credited, upper O-ring seal. While the cause of these three failures was not proven conclusively, the presence of debris observed on an O-ring is suspected in two cases and the third one showed evidence of the O-ring being twisted. No evidence of O-ring degradation was found in either case.

\section{Laboratory Surveillance - Bounding Conditions:}

Approximately 63 leak test fixtures were fabricated to the PCV design (mock-up PCVs) and have been periodically helium leak tested per ANSI N14.5 to evaluate leak tightness as a function of aging at bounding storage temperatures. In these tests, both outer and inner O-rings were installed as in real packages, with modifications made to the fixture and test procedure to allow leak testing of both O-rings. This differs from the annual certification leak testing approach which only certifies that the outer O-ring meets the $1 \mathrm{E}$ 07 ref cc/sec leaktight criterion. The annual certification test is performed on the outer O-ring, then the lid is removed and a new inner O-ring is installed and the lid is reinstalled.

The mock-up PCV fixtures have been aging for up to 5 years depending on the fixture, its aging temperatures (ranging from 200 to $450^{\circ} \mathrm{F}$ ), and the O-ring type. To date, all of the mock-up PCV fixtures at $200^{\circ} \mathrm{F}$ remain leaktight per the ANSI N14.5 room temperature helium leak test. A limited number of fixtures were taken out of test due to overheating events. Another set of fixtures were removed from test due to difficulties performing helium leak tests at elevated temperature, initially intended to evaluate seal performance at the actual aging temperature. This step was subsequently dropped. The original basis for this step was to possibly credit the O-rings for being leaktight at the actual storage temperature due to thermal expansion, but this is not required per ANSI N14.5. The O-rings are normally leak tested for a period of 3 minutes, which is more conservative than the one minute period used in annual certification. All fixtures, with one exception, were also tested for permeation to demonstrate that helium has access to the O-rings and to eliminate concern over false positive (leaktight) results [19]. 
O-rings removed from a fixture after aging at $200^{\circ} \mathrm{F}$ for 9 months showed a nominal compression set of 18 and $30 \% 30$ days after removal. O-rings aged at $300^{\circ} \mathrm{F}$ for the same period showed higher compression set (38-71\% 30 days after removal). These fixtures were still leak-tight at room temperature, but were removed from test for other reasons. In comparison, two fixtures aging at $300^{\circ} \mathrm{F}$ failed the room temperature leak test after 42 and 44 months at temperature, respectively. The O-rings from these fixtures had compression set of $65-89 \%$. Each of these conditions is illustrated in Figure 3. High compression set alone does not mean that an O-ring cannot function or remain leaktight, which is the ultimate criterion for 9975 O-ring performance. The material is still intact, serves as a release barrier, and may even bond to the mating surface over time, thus maintaining seal integrity [20]. Leak-tightness at elevated temperature may even be enhanced by thermal expansion.

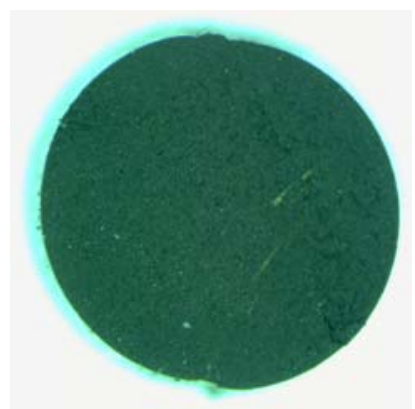

(a) New $0 \% \mathrm{CS}$

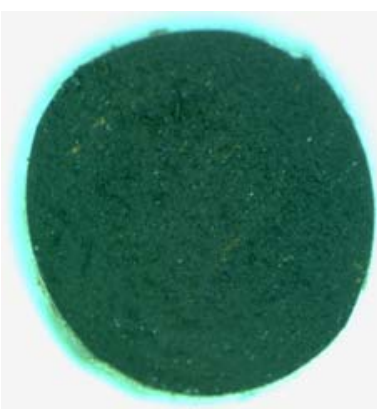

(b) Fixture 24 outer $23 \%$ CS

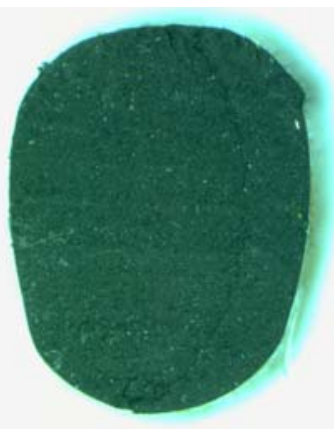

(c) Fixture 31 outer $65 \%$ CS

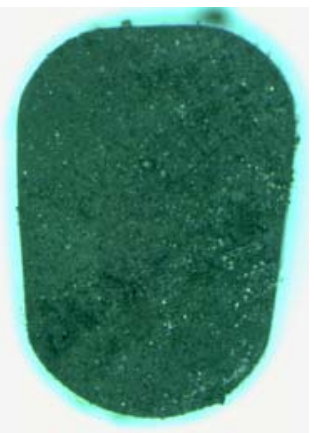

(d) Fixture 32 inner $89 \%$ CS

Figure 3. Cross-section of select o-rings with varying degrees of compression set. The $23 \%$ compression set in (b) is typical of field surveillance observations. The O-rings in (c) and (d) were removed from test after they failed to maintain leak-tightness at room temperature (following aging at $300^{\circ} \mathrm{F}$ ).

An example of leak performance vs. compression set is noted from earlier testing of the GLT O-rings (1998) after exposure to high radiation doses (100 Mrad) to impose high values of compression set. The radiation dose was not selected to represent a specific period of aging, but rather to evaluate seal integrity after a certain amount of degradation was imposed. These tests showed that O-rings with up 85\% compression set after 100 Mrad gamma were leaktight at room temperature [21].

The bounding radiation dose rate to the O-rings within the KAC storage configuration is approximately $2 \mathrm{rad} / \mathrm{hr}$ (19W payload). The dose rate to seals in packages with lower payloads is further reduced. Elastomers such as Viton ${ }^{\circledR}$ fluoroelastomer are generally resistant to radiation doses of at least $1 \mathrm{E}+05 \mathrm{rad}$. This dose represents an initial damage threshold based on changes in mechanical properties such as tensile strength or elongation and is not characterized as a failure point. Much higher doses are typically needed for severe degradation. In a highly static seal, higher doses can generally be tolerated without loss of seal performance. An upper dose limit of $1 \mathrm{E}+07 \mathrm{rad}$ (10 Mrad) is often quoted for elastomeric seals, at least based on generic design and doses imposed 
at very high dose rates, excluding the effects of elevated temperature. At $2 \mathrm{rad} / \mathrm{hr}$, an initial damage dose of $1 \mathrm{E}+05$ rad would require about 5.7 years. To accumulate a dose that would produce severe degradation would require approximately 570 years. Therefore, at the radiation dose rate anticipated in the 9975 (excluding direct contact with alpha), degradation due to radiation is not considered a significant factor for the containment vessel O-rings.

However, to address the possibility of radiation effects, some of the O-rings in certain fixtures were initially irradiated to a 12-year dose, to account for the 10+2 year shipping/storage period in KAMS. A 12-year dose at $2 \mathrm{rad} / \mathrm{hr}$ is approximately $2.1 \mathrm{E}+05$ rad, which is at or below the range likely needed to show measurable changes in mechanical properties. Even a 17 year dose at $2 \mathrm{rad} / \mathrm{hr}$ is only $3 \mathrm{E}+05 \mathrm{rad}$, which is still considered a mild and highly tolerable dose for Viton ${ }^{\circledR}$ fluoroelastomers. The marginal increase in dose for the additional 5 years is not expected to cause significant degradation, based on available data.

Based on the compression set measurements and visual examination of the O-rings removed from some of the mock-up PCV fixtures, it is clear that relaxation occurs more rapidly at $300^{\circ} \mathrm{F}$ than at $200^{\circ} \mathrm{F}$. This behavior is believed to be primarily physical in nature (rearrangement of polymer chains) rather than true chemical degradation, though the mechanical effect (loss of sealing force) may be the same. Therefore, for discussion purposes, the term "relaxation" should be distinguished from "degradation", which can have a more negative connotation. During removal of an O-ring from one of the mockup PCV fixtures at $300^{\circ} \mathrm{F}$, the O-ring actually broke apart. Some bonding to mating surfaces was also evident. However, the O-rings in these fixtures all remained leaktight at room temperature. Tensile testing of the broken O-ring indicated no significant change in mechanical properties compared to nominal values. The cause of O-ring tensile break in that case is likely related to the high localized stresses associated with removal of an aged O-ring bonded to the mating surface, and possibly a manufacturing anomaly. Such aspects are not an issue for normal seal performance.

\section{Laboratory Surveillance - Accelerated-Aging:}

Aside from actual leak performance, the most relevant material parameter for the O-rings is compression stress-relaxation (CSR). CSR is a direct measure of the sealing force exerted by the seal against mating surfaces, compared to compression set which is only a dimensional recovery measurement. The relationship between CSR and leak performance is complex and depends on several factors, but it is a strong indicator of seal performance. CSR is a standard industry approach to evaluating seal performance.

In CSR studies of O-rings for critical applications such as nuclear weapon components, a retained sealing force value of $10 \%\left(\mathrm{~F} / \mathrm{F}_{0}=0.10\right)$ is often used to define the mechanical lifetime of the seal. Leak performance at this relaxation level is likely acceptable, particularly under very static conditions, though the seal's ability to respond to changing conditions may be limited. However, this may be non-conservative and the sensitivity of the 9975 design to CSR has not been fully established. 
Baseline CSR tests performed on the 9975 O-ring compounds (with 25\% compression) indicate the seals can lose approximately $90 \%$ of initial sealing force at $~ 500$ hours and practically all sealing force at $\sim 1000$ hours at $400{ }^{\circ} \mathrm{F}$ [22]. This is consistent with the Parker Seals “continuous" temperature limit of $400^{\circ} \mathrm{F}$. The technical basis for such generic ratings is not well established as there are no criteria or test methods stated in the Parker O-Ring Handbook [23]. However, seal manufacturers strongly recommend enduser testing to confirm such limits.

Longer term CSR data were obtained at aging temperatures of $175-350{ }^{\circ} \mathrm{F}$, providing the basis for a preliminary life prediction model for the V0835-75 O-rings in KAMS. This conservative model is based primarily on long-term compression stress relaxation (CSR) experiments and Arrhenius accelerated-aging methodology. Using the principle of timetemperature superposition, all of the CSR data from different aging temperatures were used to collectively predict seal lifetime represented by either $90 \%$ or $100 \%$ loss of measurable sealing force (Figure 4) [24-26].

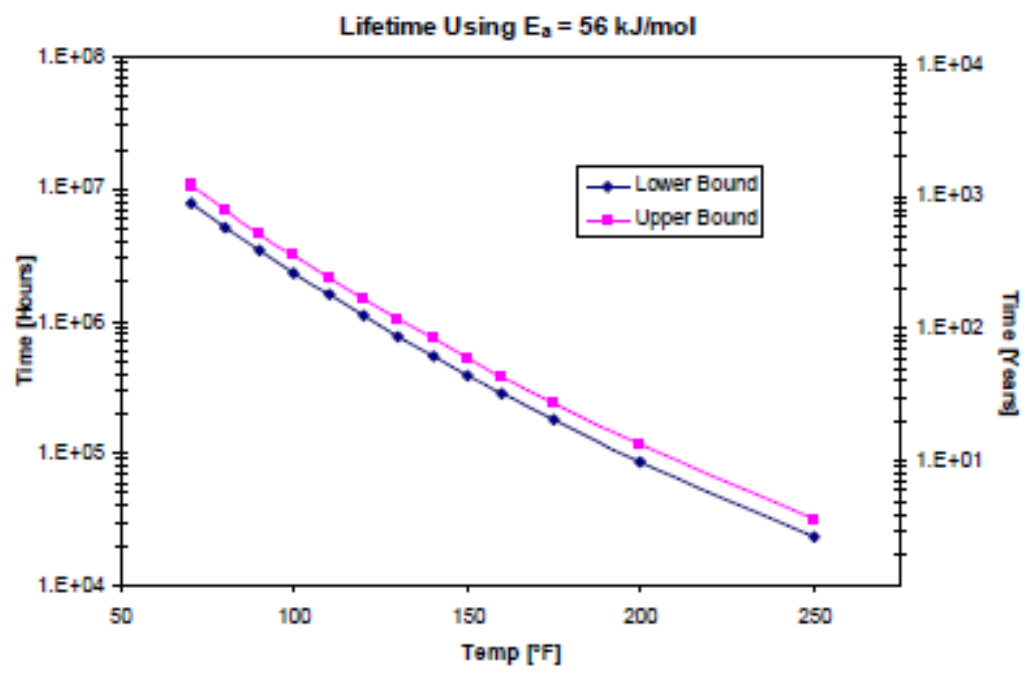

Figure 4. O-ring lifetime predictions as a function of temperature based on CSR data. The lower bound prediction correlates to $90 \%$ loss of sealing force. The upper bound prediction correlates to $100 \%$ loss of sealing force.

With regard to O-ring performance in KAMS, the model predicts that at a constant service temperature of $200{ }^{\circ} \mathrm{F}$, the seals should remain leaktight for at least 12 years. At a more realistic maximum seal temperature of $175^{\circ} \mathrm{F}$, the preliminary model predicts a seal lifetime of approximately 20-25 years. Assuming an average payload of $12 \mathrm{~W}$ and a peak ambient temperature of $106^{\circ} \mathrm{F}$ (conservative), the maximum O-ring temperature in the 9975 is approximately $144^{\circ} \mathrm{F}$. At $150^{\circ} \mathrm{F}$ (provides a slight margin) the model predicts a service life of approximately 45-60 years. Given that the peak temperatures assumed are not sustained on a continuous basis, the amount of relaxation expected in actual packages is expected to be even less. Therefore, based on available data, the Orings are expected to perform reliably for the 15 year storage period with ample margin. 
It must be noted that the model assumes a constant degradation mechanism and single activation energy over the entire temperature range and life of the seals in storage. It is possible that the degradation mechanism and activation energy of the degradation process could change at some point, altering the life prediction model. Such changes may occur due to long-term oxidation of the elastomer or some other mechanism that has not yet been observed. Therefore, evaluation of the seals continues to determine if such changes are possible and to interpret possible impacts on the storage facility.

\section{$\underline{\text { Leak Rate/CSR Correlation }}$}

The acceptance criterion for Model 9975 O-ring performance is to maintain a room temperature leak rate of $<1 \mathrm{E}-07 \mathrm{ref} \mathrm{cc} / \mathrm{sec}(<2 \mathrm{E}-07 \mathrm{cc} / \mathrm{sec} \mathrm{He})$. However, the mechanical properties that correlate to this leak rate have not been established. Therefore, SRNL is currently performing experiments to correlate leak rate with CSR. Figure 5 compares the time to failure based on model predictions from CSR data with the actual time to leak failure in the mock-up PCV fixtures. These two approaches show general agreement at $\sim 350-400^{\circ} \mathrm{F}$, and the CSR-based model provides conservative predictions at lower temperatures.

\section{Celotex ${ }^{\circledR}$ Performance - Fire Resistance, Criticality Control, and Impact Resistance}

\section{Field Surveillance - Actual Conditions:}

Under normal storage conditions, the anticipated predominant degradation mechanism for fiberboard in 9975 packages is slow pyrolysis due to elevated temperature and/or elevated humidity. This degradation mechanism leads to loss of material, reduced strength, loss of density, decrease in thermal conductivity, reduced assembly height and challenge to criticality controls. The presence of an internal heat source will lead to a moisture gradient within the fiberboard. Regions of elevated moisture can experience enhanced rates of the above degradation mechanism, as well as the possible growth of mold. Off-normal circumstances which could introduce additional degradation mechanisms include elevated total moisture levels (leading to mold and compaction) and infestation (leading to fiberboard consumption).

After several years of storage in KAC, only one shipping package (9975-01710) has been found during the NDE process with mold on the fiberboard (Figure 6). Further inspection identified regions of mold on both the upper and lower fiberboard assemblies, elevated moisture levels in the regions of mold, and the axial gap above the fiberboard exceeded the 1 inch maximum criterion (consistent with compaction of the lower fiberboard layers). Twelve additional packages in KAMS have been identified through activities other than NDE that failed the axial gap criterion. In a majority of these packages, the fiberboard contained mold and regions of elevated moisture levels. The moisture levels were generally highest in the bottom fiberboard layers, leading to compaction and the increased axial gap. 


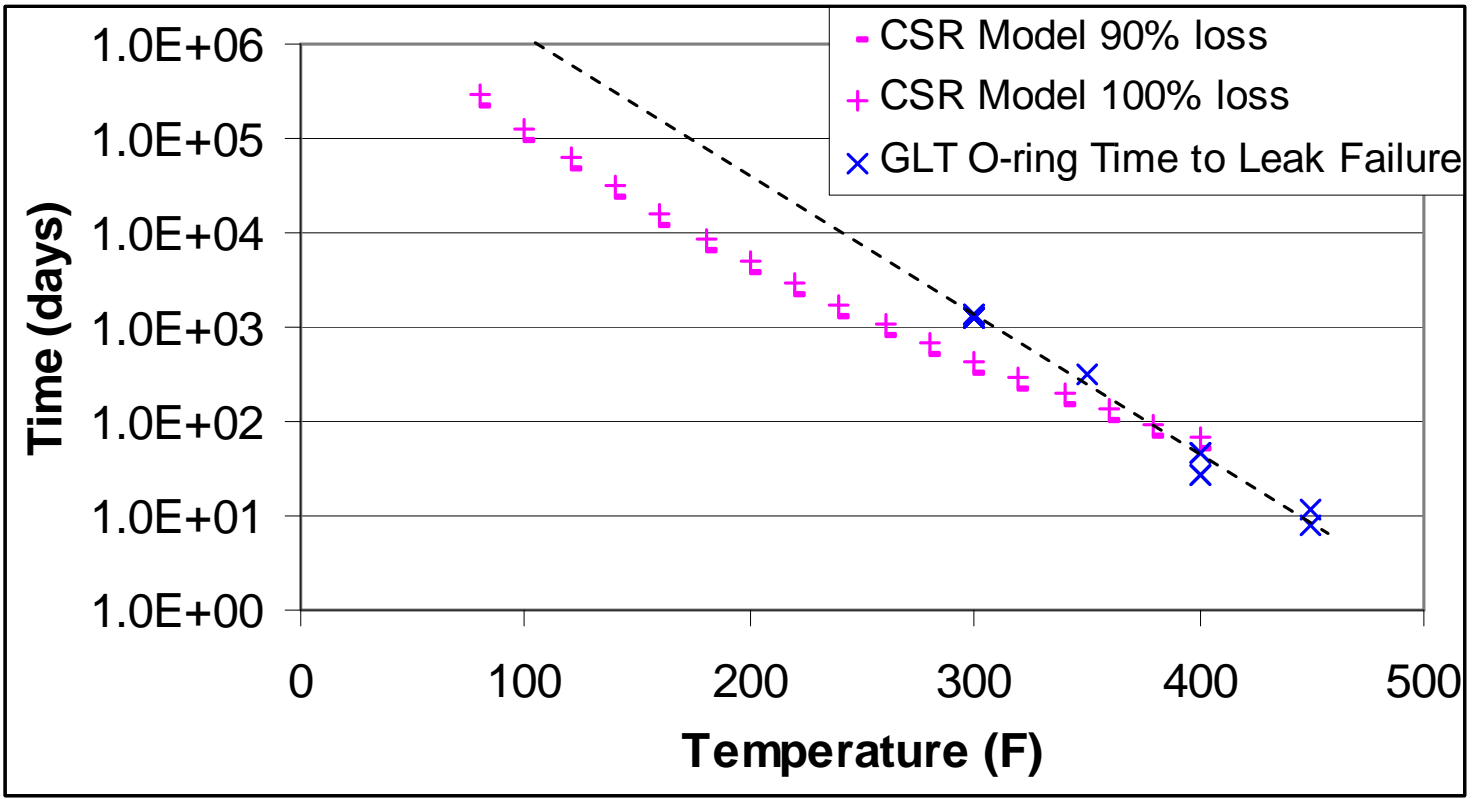

Figure 5. Leakage-based service life data for GLT O-rings (from mock-up PCV fixtures with room temperature leak rate failures) compared to life predictions from GLT O-ring compression stress relaxation (CSR) data.

Six packages have received a more extensive destructive examination, including measurement of thermal and mechanical properties of the fiberboard [27-32]. These packages had been stored in KAMS for up to 7 years. Mold was found on the lower assembly of one DE package (9975-02028). In the absence of data from the same fiberboard at beginning of life, the extent to which the fiberboard properties might have changed during service cannot be estimated. However, the thermal conductivity, compressive strength and density of fiberboard in each of these packages were consistent with that measured for unaged material. Therefore, it is concluded that the fiberboard in these packages did not degrade significantly.

Two packages were identified at Hanford to be infested with drugstore beetles, which were consuming the fiberboard overpack. These beetles are capable of consuming all constituents of the fiberboard assembly, although the glue layers were attacked preferentially in this case. Numerous other species of insect or other pest are capable of consuming fiberboard, although no further cases of infestation in 9975 shipping packages have been identified and this particular infestation seems to be limited to just the two packages [33]. 


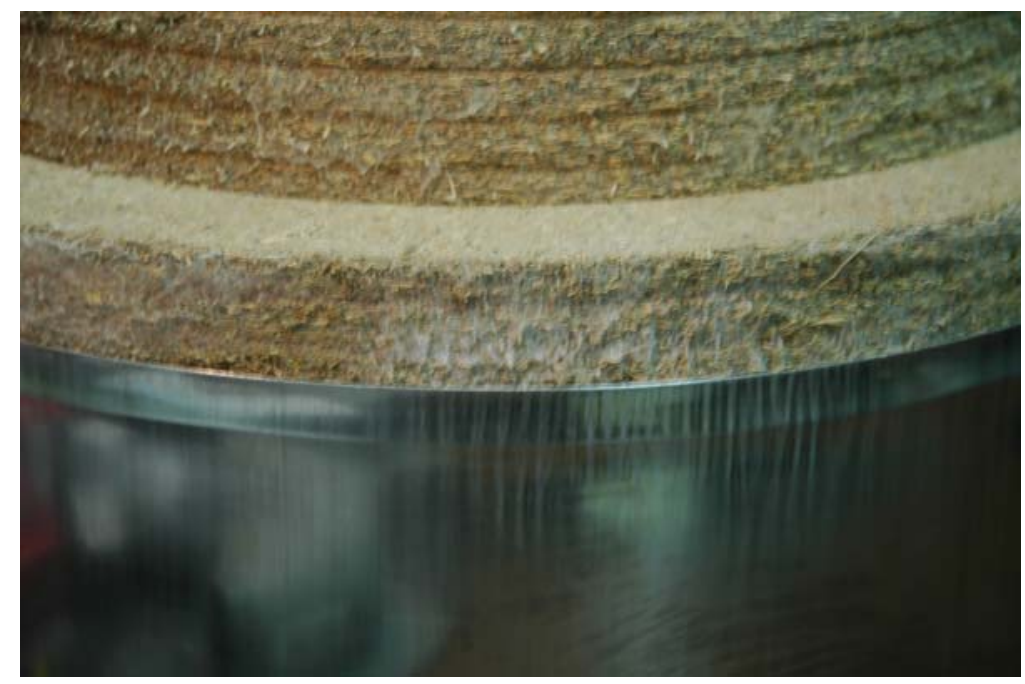

Figure 6. Example of moldy fiberboard seen on 9975-01710 from KAMS.

\section{Laboratory Surveillance - Bounding Conditions:}

Laboratory surveillance has been performed on small-scale fiberboard samples to track changes in the mechanical, thermal and physical properties during short and long-term aging. Aging environments were selected to provide conditions typical of KAC service as well as bounding to that service. Following baseline data, the maximum exposure periods in the various environments range from 17 to 270 weeks (through October 2010).

The highest temperature environment is $250^{\circ} \mathrm{F}$, which is the operating limit identified for fiberboard in the 9975 SARP [6,7]. Current calculations show that portions of the fiberboard could approach this value during extreme conditions, although these events would likely be relatively short-term. In the more moderate temperature environments, elevated humidity levels are combined with elevated temperature.

For the tested environments, short-term exposures tend to produce property changes based primarily on changes in sample moisture content. The fiberboard readily gains or loses moisture in response to the surrounding environment, and the moisture content has a strong influence on fiberboard properties. The longer-term exposures show the impact of material degradation.

While the moisture content of fiberboard will tend to seek equilibrium with the humidity of the surrounding air, the 9975 drum provides a significant degree of isolation between the fiberboard and the external environment. An upper assembly exposed directly to the ambient air experiences a variation in weight of $\sim 1.5 \%$ as a result of seasonal humidity changes. When placed inside a closed 9975 drum, however, the variation is reduced approximately 50X. The moisture which is contained in the fiberboard when it is placed in the drum will likely define the humidity level inside the drum for a long time. 


\section{Mechanical Properties}

Mechanical strength of the fiberboard is required primarily for energy absorption during an impact or drop event. The compression test produces a stress-strain curve, with the area under the curve being proportional to the energy absorbed. The area under the stress-strain curve up to a strain of $40 \%$ is used as a metric for comparing results between samples. Figure 7 shows the variation in this metric over time for samples conditioned at several elevated temperatures, and for samples conditioned at $185^{\circ} \mathrm{F}\left(85^{\circ} \mathrm{C}\right)$ with several humidity levels. Noticeable declines over time in energy absorption capability are seen for elevated temperatures of $215^{\circ} \mathrm{F}$ and greater, and for elevated humidity levels at $185^{\circ} \mathrm{F}$. The Figure 7 data apply to material tested in the parallel orientation (typical of a package crushed from the side). The same trends are observed, although at a slower rate, for material tested in the perpendicular orientation (typical of an impact to the top of a package).

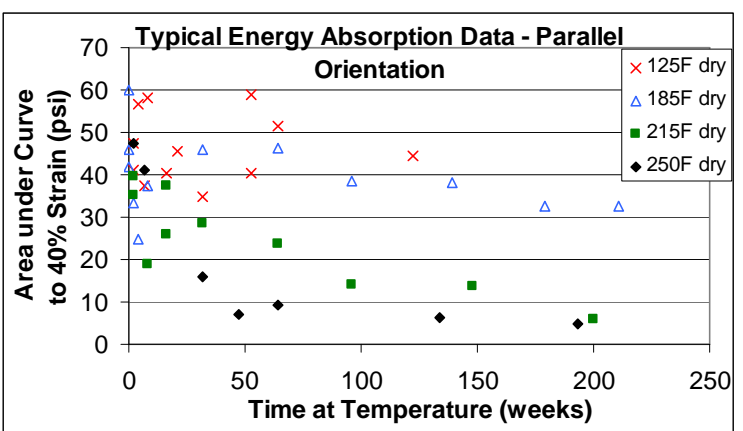

(a)

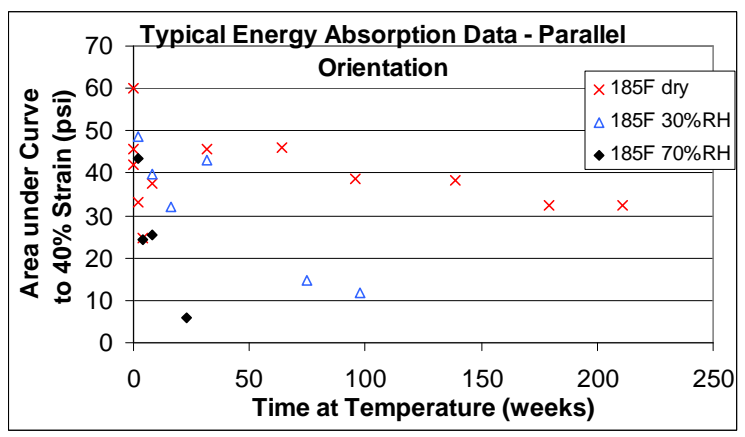

(b)

Figure 7. Area under the compression stress-strain curve up to $40 \%$ strain, for parallel orientation samples. Samples in (a) were conditioned in dry environments, at the temperatures noted. Samples in (b) were conditioned at $185^{\circ} \mathrm{F}$, at the humidity levels noted. All samples shown are from a single package source designation to reduce the effect of package-to-package variation.

\section{Thermal Properties}

Thermal conductivity of fiberboard samples is measured at three mean temperatures -77 , 122 and $185^{\circ} \mathrm{F}\left(25,50\right.$ and $\left.85^{\circ} \mathrm{C}\right)$. The same trends are seen in thermal conductivity for each test temperature. Thermal conductivity is also measured for two orientations - with heat flow parallel to the fiberboard layers (radial) and with heat flow perpendicular to the fiberboard layers (axial). Significant changes in thermal conductivity result from conditioning in elevated temperature and humidity environments, as shown in Figure 8. While the elevated humidity exposures are of relatively short duration, the rate of degradation from each environment is seen in the slope of the data for each data set.

In Figure 8 (a), the step decrease between thermal conductivity at time 0 and subsequent data reflects a change in the moisture content of the samples. The initial exposure to elevated temperature drives off most of the moisture within the material, with a resulting decrease in the thermal conductivity. This change is reversible if the material is allowed 
to re-absorb moisture. However, the decrease in thermal conductivity during extended exposure to the aging environments is not reversible.

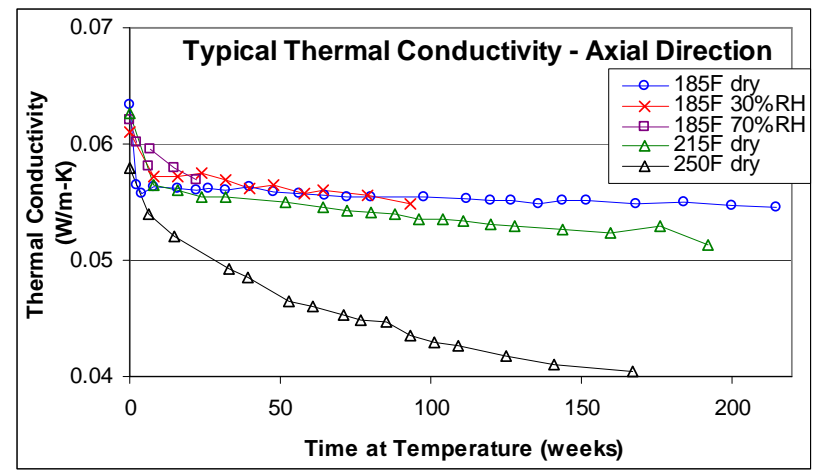

(a)

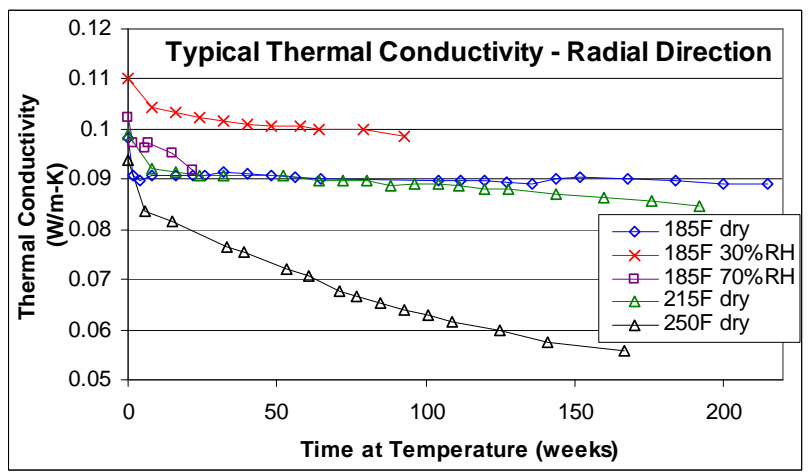

(b)

Figure 8. Thermal conductivity data for $77 \mathrm{~F}$ mean temperature following conditioning in several environments. (a) axial orientation, (b) radial orientation.

The specific heat capacity is measured following different intervals in various environments, including elevated temperature and/or humidity. In general, the specific heat capacity data show significant scatter, but do not show significant degradation [34].

\section{Physical Properties}

Fiberboard weight, dimensions and density change as a result of change in moisture content and/or aging. These properties for samples aged in several environments are summarized in [34]. For example, Figure 9 shows the weight change experienced in several dry and humid environments. In this figure, the weight is normalized to its initial conditioned value to provide a common point of comparison across different samples.

Among the nominally dry environments, each of the physical properties degrades faster as the temperature increases. At a given temperature, each property degrades faster at higher humidity levels. However, there may be a humidity threshold below which the humidity level does not affect the degradation rate. The difference in physical properties is small for samples conditioned in a $185^{\circ} \mathrm{F}$ dry oven and a $185^{\circ} \mathrm{F} 30 \%$ humidity chamber. 


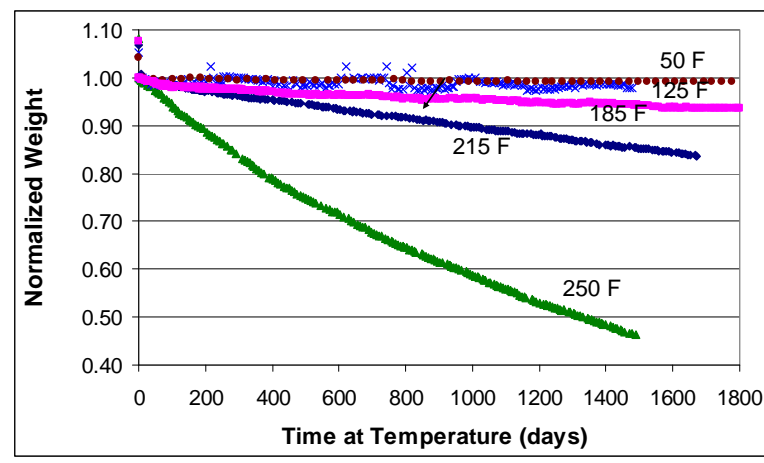

(a)

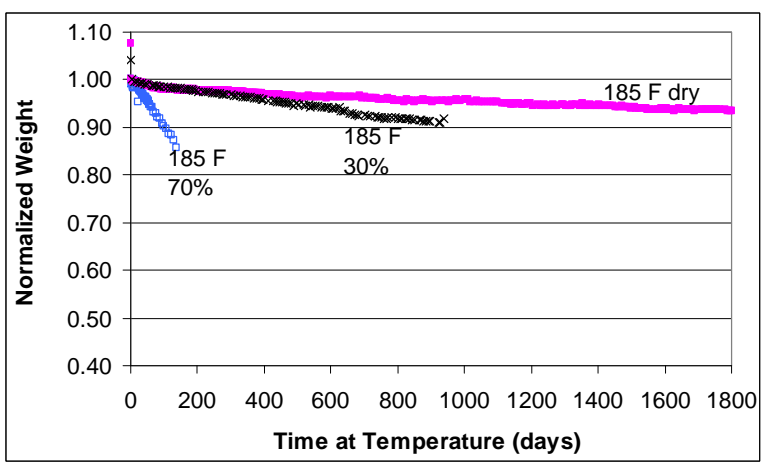

(b)

Figure 9. Relative weight change for fiberboard samples conditioned in several environments. Samples in (a) were conditioned in dry environments, at the temperatures noted. Samples in (b) were conditioned at $185^{\circ} \mathrm{F}$, at the humidity levels noted.

\section{Other}

Limited testing to date on full 9975 packages shows that some environments can have a strong influence on package performance. In particular, as the internal heat load creates a thermal gradient within the fiberboard, the moisture in the fiberboard will also form a gradient. In general, higher moisture levels will develop in the cooler regions of the fiberboard. In extreme conditions, if regions of the fiberboard are heated high enough, the water in those regions will evaporate, but the water vapor will not easily escape the drum. Therefore, it will tend to condense in the coolest portions of the drum. The temperature distribution will define the extent of moisture redistribution.

This behavior has been observed in three instrumented test packages that were heated internally as well as from the outside. Each package started with typical fiberboard moisture levels. In all three cases, the bottom fiberboard layers eventually became saturated with moisture.

Given this condition of moisture redistribution, which could occur during transport or storage, several results might be expected, as follows.

- The moisture gradient will create a gradient in fiberboard properties. Regions of increased moisture content will have increased thermal conductivity and decreased strength.

- $\quad$ Regions of elevated moisture will experience accelerated degradation rates.

- Reduced compression strength of the bottom fiberboard layers leads to compaction and an increased axial gap at the top of the package.

- The regions of higher moisture, combined with moderate temperatures (which might exist locally in the package or develop following a transient event) will likely support the growth of mold.

- Relatively large-scale movement of moisture through the fiberboard may leach chlorides from the fiberboard and concentrate them on either the drum or shield, leading to conditions favorable for accelerated corrosion of those components. 


\section{ALTERNATE AND OTHER MATERIALS DISCUSSION}

As previously discussed, the initial effort to qualify 9975 containers for storage in KAC assessed the GLT O-rings and Celotex ${ }^{\circledR}$ cane fiberboard materials to support a 2 year shipping plus 10-year interim storage period [21,2]. Thus, the data obtained for these materials has been ongoing since the Surveillance and Storage Program was initiated and these results have been used for the justification to extend the life of the 9975 packages currently stored in KAMS from 10 to 15 years. Over time, GLT-S Viton ${ }^{\circledR}$ O-rings and softwood fiberboard Celotex ${ }^{\circledR}$ materials were also approved as alternate materials in the 9975 shipping and storage package and an aging study was initiated for these alternate materials to validate their performance against the initial materials used. To date, the baseline and aging properties of the GLT-S and the softwood fiberboard alternate materials are generally consistent with those of the GLT and cane fiberboard properties, respectively. Surveillance efforts for the GLT-S and softwood fiberboard materials are ongoing to ensure their response is consistent with the GLT and cane fiberboard properties.

Other materials in the 9975 packaging subject to aging include the lead shielding assembly and the stainless steel drum. In some packages the lead shielding has shown lead carbonate corrosion. Studies performed by SRNL's Materials Science and Technology (MS\&T) directorate estimated the maximum corrosion rate for the lead assembly at 2 mils per year [35]. At this rate, analysis shows that a minimum of twenty years would be required to have an unacceptable impact on lead shielding performance. Non-destructive surveillance activities of the lead shield need to be continued and the status of the lead shield integrity will be re-assessed at the 15 year timeframe. No additional discussion of the lead shielding will be provided herein. In the event of moisture migration within the fiberboard, chlorides may be leached out of the fiberboard and potentially lead to stress corrosion cracking of the drum. No evidence of this type of corrosion has been observed in any of the packages stored in KAMS examined to date.

Previous analysis of the outer drum for the 9975 shipping package showed that external corrosion was not a concern for the 12- year period that included transportation and storage [36]. Based on the findings from the 9975 Storage Surveillance Program in conjunction with reference [36], this analysis is valid for the 15 year 9975 justification as well.

A similar analysis of components inside the package showed that internal corrosion was also not a concern, during the same 12-year period that included transportation and storage [37]. This analysis is valid for the 15 year 9975 justification as well.

Finally, from reference [38] hydrogen embrittlement will not cause the ductility of the PCV to be reduced to the point of concern over the 12-year period that includes transportation and storage. This analysis is valid for the 15 year 9975 justification as well. 
The Shipping Package Qualification and Storage Surveillance Program for the shipping package specifies acceptable damage criteria as well as the need for periodic inspections and surveillance of the package [9]. This Surveillance and Storage program ensures that no components (including the fiberboard insulation, O-rings, etc.) are allowed to degrade to the point that a package's basic functions are adversely affected.

\section{CONCLUSIONS \& OBSERVATIONS}

1. Surveillance data have been obtained on field O-rings taken from 195 Model 9975 packages after various storage periods (up to 8 years) in the KAC. Thus far, no significant O-ring degradation has been observed.

2. Mock-up PCV fixtures with O-rings aged at 200F for 4+ years on a continuous basis remain leaktight by ANSI N14.5 definition. A limited number of fixtures have recently failed the room temperature leaktight criterion after aging at $300 \mathrm{~F}$ for similar periods. The cause and impact of these failures has not been fully evaluated. However, for normal storage conditions in KAC, the impact is believed to be negligible or minimal. The 300F temperature is a design limit for the containment vessel that far exceeds the conditions normally anticipated in the KAC. The leak testing approach provides an excellent method for monitoring Oring performance real-time at bounding conditions. These results indicate longerterm stability at lower temperatures.

3. Accelerated-aging tests using CSR as a parameter to measure seal performance indicate that the O-rings are capable of retaining measureable sealing force for many years. Life prediction models based on CSR data indicate several decades at normal storage conditions are possible. However, a "cliff” response (sharp increase in degradation rate) and non-Arrhenius behavior at lower temperatures cannot currently be excluded, although it is not anticipated based on available data.

4. The level of relaxation or sealing force decay that is required to cause leak rate failure is believed to be extremely high, however, it has not yet been determined. During normal storage in KAC, the level of degradation reached in a 15-year period is not expected to challenge the ability of the O-rings to maintain leaktightness.

5. Two fiberboard issues seen to date which have the potential to compromise fiberboard integrity over time (excess moisture and beetle infestation) are not representative of compliant packages.

6. Degradation of physical, mechanical and thermal fiberboard properties in compliant packages at storage temperatures is generally slow and will provide significant time before required margins are compromised. Fiberboard properties measured on packages following up to 7 years in storage indicate the material to have experienced no significant degradation. It is further expected that these 
packages would continue to show no significant degradation for up to 15 years in storage. Accordingly, compliant packages stored under such conditions are expected to continue to meet minimum requirements for $\mathrm{KAC}$ for thermal resistance, criticality control, and impact resistance for up to 15 years in storage.

7. Based on laboratory testing, the continued integrity of fiberboard in storage is impacted by the redistribution of normal levels of fiberboard moisture due to an internal heat load. This can lead to local regions with sufficient moisture to support mold growth. Such behavior will typically be most pronounced in packages with higher heat loads. In KAMS, only a small population of actual drums has experienced this characteristic. This limited population has been found with local regions of elevated moisture levels in the fiberboard resulting in mold and loss of integrity (generally in the bottom layers of the fiberboard). Even with elevated moisture in the bottom fiberboard layers, the thermal analysis shows the 9975 can perform its intended function during a fire scenario because of its robust construction. However, the extent to which this condition and its accompanying growth of mold will accelerate fiberboard degradation rates is currently unknown.

8. Based on the data obtained to date and projected performance of the 9975 packages in the KAMS facility, the 9975 packages are expected to maintain the minimum safety requirements for a period of 15 years in KAMS storage. This justification is established with the stipulation that surveillance activities will continue throughout this extended time to ensure the continued integrity of the 9975 materials of construction and to further understand the currently identified degradation mechanisms. Additional data collected will be re-evaluated to further validate these conclusions and for future life extension. 
SRNS-STI-2010-00763

Rev. 0

\section{REFERENCES}

(1) SFS-ENG-99-0085, Rev. 0, "Summary and Guide to the 9975 Container Qualification Program for 10-Year Storage of Plutonium in Building 105-K", March 22, 1999

(2) WSRC-TR-2003-00247, Rev. 2, "Summary and Matrix for the 9975 and SAFKEG Shipping Package Qualification Programs for Extended Storage of Plutonium in KAMS (U)”, July 2004

(3) SRNS-TR-2008-00290, Rev. 0, "Summary and Matrix: 9975 Shipping Package Qualification Program for Extended Storage of Plutonium in the KArea Complex (U)", November 2008

(4) WSRC-TR-2001-00286, Rev. 5, "The Savannah River Site Surveillance Program for the Storage of 9975/3013 Plutonium Packages in KAC (U)", November 2010

(5) DOE-STD-3013-2004, "DOE Standard Stabilization, Packaging, and Storage of Plutonium Bearing Materials”, April 2004

(6) WSRC-SA-2002-00008, Rev 0, "Safety Analysis Report for Packaging Model $9975 \mathrm{~B}(\mathrm{M}) \mathrm{F}-85$ ”

(7) S-SARP-G-00003, Rev.0, "Safety Analysis Report for Packaging Model 9975 $\mathrm{B}(\mathrm{M}) \mathrm{F}-96 ”$

(8) ASTM Spec C208, "Standard Specification for Cellulosic Fiber Insulating Board”, ASTM International, latest revision 2008

(9) WSRC-SA-2002-00005, Rev 4, "K-Area Complex - Documented Safety Analysis"

(10) LA-UR-00-3246, Rev. 1, "Integrated Surveillance Program in Support of Long-Term Storage of Plutonium Bearing Materials”, March 2000

(11) WSRC-TR-2008-00163, "Baseline characterization of Viton ${ }^{\circledR}$ GLT-S ORings for Model 9975 shipping packages in KAMS (U)”, T. E. Skidmore, E.N. Hoffman, May 2008

(12) SRT-MTS-99-4069, "Chloride Analysis of Celotex ${ }^{\circledR}$ Cane Fiberboard (U)", P.R. Vormelker to D.H. Poss, July 14, 1999

(13) WSRC-TR-98-00439, "Performance Evaluation of O-Ring Seals in Model 9975 Packaging Assemblies”, T.E. Skidmore, December 1998 
(14) SRNS-TR-2008-00054, Rev. 0, "Task Technical and Quality Assurance plan for Accelerated Aging of Viton ${ }^{\circledR}$ GLT-S O-rings for Model 9975 Shipping Packages in KAMS (U)”, E.N. Hoffman, T.E. Skidmore, January 2009

(15) M-CLC-K-00747, "Thermal Model Study of the 9975 Package with Moisture Degraded Fiberboard in KAMS Facility”, N,K. Gupta, May 2010

(16) N-NCS-K-00021, Rev.2 "Nuclear Criticality Safety Evaluation: Controls and Limits for Storage of Shipping Packages in KAMS (U)”, April 2009

(17) M-CLC-K-00657, Rev. 1, "Structural Analysis of 9975 Package Subjected to Two Forklift Truck Impact”, T. Wu, December 2005

(18) OBU-NMM-2004-00060, “KAMS T-1 Temperature Readings”, S. M. Herlihy to T. K. Houghtaling, Inter-Office Memorandum, March 25, 2004

(19) SRNL-TR-2010-00136, "Fifth Interim Status Report: Model 9975 PCV ORing Fixture Long-Term Leak Performance”, W.L. Daugherty and E.N. Hoffman, October 2010

(20) WSRC-TR-2007-00073, Rev. 0, "Second Interim Status Report: Model 9975 PCV O-Ring Long-Term Leak Performance (U)”, June 2007

(21) WSRC-TR-99-00041, "Leak Testing of Artificially-Aged O-Ring Seals for Model 9975 Packaging Assemblies (U)”, T.E. Skidmore, February 1999

(22) WSRC-TR-2004-00331, "Baseline Compression Set and Stress-Relaxation Behavior of Model 9975 Shipping Package O-Rings (U)”, T.E. Skidmore, December 2004

(23) Parker O-ring Handbook, ORD-5700, Parker Seals, O-Ring Division, 2001

(24) SRNS-TR-2009-00259, "Lifetime Prediction for Model 9975 O-rings in KAMS (U)”, E.N. Hoffman, T.E. Skidmore, November 2009

(25) CASS Conference, "Aging and Surveillance of Viton ${ }^{\circledR}$ GLT O-rings in Model 9975 Shipping Packages”, T.E. Skidmore, E.N. Hoffman, W.L. Daugherty, K.A. Dunn

(26) Proceedings of the ASME 2010 Pressure Vessels \& Piping Division / K-PVP Conference, PVP2010, July 18-22, 2010, Bellevue, Washington, PVP 201025106, "Long-Term leak Tightness of O-Ring Seals in the 9975 Shipping Package”, E.N. Hoffman, T.E. Skidmore, W. L. Daugherty.

(27) WSRC-TR-2005-00273, Rev. 1, "Destructive Examination of Shipping Package 9975-02234”, W.L. Daugherty, September 2005 
SRNS-STI-2010-00763

Rev. 0

(28) WSRC-TR-2006-00162, "Destructive Examination of Shipping Package 9975-00826”, W. L. Daugherty, May 2006

(29) WSRC-STI-2007-00558, "Destructive Examination of Shipping Package 9975-00600”, W. L. Daugherty, October 2007

(30) SRNS-STI-2008-00019, "Destructive Examination of Shipping Package 9975-05128”, W. L. Daugherty, August 2008

(31) SRNL-STI-2009-00763, "Destructive Examination of Shipping Package 9975-02028”, W. L. Daugherty and T. M. Stefek, December 2009

(32) SRNL-STI-2010-00654, "Destructive Examination of Shipping Package 9975-02168”, W. L. Daugherty, November 2010

(33) S-TRT-G-00018, "Interim Report on the Drugstore Beetle Investigation", December 18, 2007

(34) Proceedings of the ASME 20 Pressure Vessel \& Piping Division K-PVP Converence, July 18-20, 2010, Bellevue, WA, “Aging Model for Can Fiberboard Overpack in the 9975 Shipping Package”, W.L. Daugherty and S.P. Harris

(35) WSRC-TR-2006-00094, "Corrosion of Lead Shielding in Model 9975 Package (U)”, K.H. Subramanian, March 2006

(36) WSRC-TR-98-00454, "External Corrosion of Model 9975 Packaging Container (U)”, P.R. Vormelker, January 1999

(37) WSRC-TR-99-00030, "Internal Corrosion Analysis of Model 9975 Packaging Containing Pu or $\mathrm{PuO}_{2}$ During Shipping and Storage (U)”, P.R. Vormelker, January 1999

(38) WSRC-TR-99-00001, "Evaluation of Hydrogen Embrittlement of 9975 Shipping Package Containment Vessels (U)”, W.L. Daugherty, January 1999 
CC: J. S. Bellamy, 773-41A G. T. Chandler, 773-A W. L. Daugherty, 773-A

K. A. Dunn, 773-41A B.A. Eberhard, 105-K M.F. Gibson, 105-K T.J. Grim, 105-K E.R. Hackney, 705-K M.K. Hackney, 705-K E.N. Hoffman, 773-A R.L. Huffines, 705-K N.C. Iyer, 773-41A D.R. Leduc, 773-41A M.J. Lewczyk, 704-K J.W. McClard, 705-K J.W. McEvoy, 730-4B D.L. Melvin, 705-K T.M. Monahon, 705-K J.L. Murphy, 773-41A A.C. Reedy, 705-K T.E. Skidmore, 730-A Document Control 